\title{
(6) OPEN ACCESS \\ The Copenhagen Consensus Conference 2016: children, youth, and physical activity in schools and during leisure time
}

Jens Bangsbo, ${ }^{1}$ Peter Krustrup ${ }^{1,2}$ Joan Duda ${ }^{3}$ Charles Hillman, ${ }_{1}^{4}$ Lars Bo Andersen, ${ }^{5,6}$ Maureen Weiss, ${ }^{7}$ Craig A Williams, ${ }^{8}$ Taru Lintunen, ${ }^{9}$ Ken Green, ${ }^{10}$

Peter Riis Hansen, ${ }^{11}$ Patti-Jean Naylor, ${ }^{12}$ Ingegerd Ericsson, ${ }^{13}$ Glen Nielsen, ${ }^{14}$ Karsten Froberg, ${ }^{15}$ Anna Bugge, ${ }^{15}$ Jesper Lundbye-Jensen, ${ }^{1}$ Jasper Schipperijn, ${ }^{15}$ Symeon Dagkas, ${ }_{16}^{16}$ Sine Agergaard, ${ }_{1}^{17}$ Jesper von Seelen, ${ }_{1}^{18}$ Charlotte Østergaard, ${ }^{19}$ Thomas Skovgaard, ${ }^{15}$ Henrik Busch, ${ }^{20}$ Anne-Marie Elbe ${ }^{1}$

For numbered affiliations see end of article.

\section{Correspondence to} Professor Peter Krustrup, Department of Nutrition, Exercise and Sports, University of Copenhagen, Copenhagen 2100-Ø, Denmark; pkrustrup@nexs.ku.dk

Accepted 10 May 2016 Published Online First 27 June 2016

\section{CrossMark}

To cite: Bangsbo J,

Krustrup P, Duda J, et al. $\mathrm{Br}$ J Sports Med

2016:50:1177-1178.

\section{ABSTRACT}

From 4 to 7 April 2016, 24 researchers from 8 countries and from a variety of academic disciplines gathered in Snekkersten, Denmark, to reach evidence-based consensus about physical activity in children and youth, that is, individuals between 6 and 18 years. Physical activity is an overarching term that consists of many structured and unstructured forms within school and out-of-school-time contexts, including organised sport, physical education, outdoor recreation, motor skill development programmes, recess, and active transportation such as biking and walking. This consensus statement presents the accord on the effects of physical activity on children's and youth's fitness, health, cognitive functioning, engagement, motivation, psychological well-being and social inclusion, as well as presenting educational and physical activity implementation strategies. The consensus was obtained through an iterative process that began with presentation of the state-of-the art in each domain followed by plenary and group discussions. Ultimately, Consensus Conference participants reached agreement on the 21-item consensus statement.

THEME 1: PHYSICAL ACTIVITY IN CHILDREN AND YOUTH: FITNESS AND HEALTH

- Cardiorespiratory and muscular fitness levels in children and youth are strong predictors of future cardiometabolic disease, such as coronary artery disease and diabetes mellitus.

- Vigorous exercise has a marked favourable impact on cardiometabolic fitness and other cardiovascular risk factors in children and youth.

- Frequent moderate-intensity and, to a lesser extent, low-intensity exercise improves cardiometabolic fitness in children and youth.

- Physical activity is important in the treatment of many chronic diseases in children and youth.

- Children and youth participating in leisure-time sports have higher levels of physical activity, fitness and overall cardiometabolic health, and better musculoskeletal health when involved in weight-bearing sports.

- Field-based testing of cardiorespiratory fitness and waist/height scores, is a valuable tool for preliminary assessment and identification of children and youth with cardiometabolic risk.

\section{THEME 2: PHYSICAL ACTIVITY IN CHILDREN AND YOUTH: COGNITIVE FUNCTIONING}

- Physical activity and cardiorespiratory fitness are beneficial to brain structure, brain function and cognition in children and youth.

- Physical activity before, during and after school promotes scholastic performance in children and youth.

- A single session of moderate physical activity has an acute benefit to brain function, cognition and scholastic performance in children and youth.

- Mastery of fundamental movement skills is beneficial to cognition and scholastic performance in children and youth.

- Time taken away from academic lessons in favour of physical activity has been shown to not come at the cost of scholastic performance in children and youth.

\section{THEME 3: PHYSICAL ACTIVITY IN CHILDREN AND YOUTH: ENGAGEMENT, MOTIVATION, PSYCHOLOGICAL WELL-BEING}

- Engagement in physical activity has the potential to positively influence psychological and social outcomes for children and youth, such as selfesteem and relationships with peers, parents and coaches.

- An autonomy supportive, mastery focused and caring/socially supportive environment, positively influences children's and youths' selfdetermined motivation, physical activity behaviour and holistic well-being.

- Close friendships and peer group acceptance in physical activity are positively related to perceived competence, intrinsic motivation and participation behaviour in children and youth.

- Parental attitudes and behaviours are strongly related to children's and youths' selfperceptions, motivation and physical activity.

- Systematic and deliberate training enables teachers and coaches to create a positive motivational environment for children and youth. 
- Physical activity-based positive youth development programmes that have an intentional curriculum and deliberate training are effective at promoting life skills (eg, interpersonal, self-regulation skills) and core values (eg, respect and social responsibility) in children and youth.

\section{THEME 4: PHYSICAL ACTIVITY IN CHILDREN AND YOUTH: SOCIAL INCLUSION AND PHYSICAL ACTIVITY IMPLEMENTATION STRATEGIES}

- Participation of children and youth in physical activity and sport is influenced by socioeconomic status, gender, ethnicity, sexual orientation, skill level and disabilities.

- Culturally and contextually relevant physical activity opportunities help to recognise and account for the diverse lives of children and youth, and to promote social inclusion.

- Social inclusion can be promoted by providing equal access to opportunities within physical activity and sports settings regardless of children and young people's social, cultural, physical and demographic characteristics.

- Whole school approaches and the provision of physical activity-conducive environments such as bike lanes, parks and playgrounds, are both effective strategies for providing equitable access to, and enhancing physical activity for, children and youth.

\section{Author affiliations}

${ }^{1}$ Department of Nutrition, Exercise and Sports (NEXS), University of Copenhagen, Copenhagen, Denmark

${ }^{2}$ Sport and Health Sciences, University of Exeter, Exeter, UK

${ }^{3}$ School of Sport, Exercise and Rehabilitation Sciences, University of Birmingham, Birmingham, UK

${ }^{4}$ Department of Kinesiology and Community Health, University of Illinois, Urbana, Illinois, USA
${ }^{5}$ Faculty of Teacher Education and Sport, Sogn and Fjordane University Colleage, Sogndal, Norway

${ }^{6}$ Department of Exercise Epidemiology, Center of Research in Childhood Health, University of Southern Denmark, Odense, Denmark

${ }^{7}$ Department of Kinesiology, University of Minnesota, Minneapolis, Minnesota, USA

${ }^{8}$ Children's Health and Exercise Research Centre, Sport and Health Sciences,

University of Exeter, Exeter, UK

${ }^{9}$ Faculty of Sport and Health Sciences, University of Jyväskylä, Jyväskylä, Finland

${ }^{10}$ University of Chester, Chester, UK

${ }^{11}$ Department of Cardiology, Gentofte University Hospital, Hellerup, Denmark

${ }^{12}$ School of Exercise Science, Physical and Heal, University of Victoria, Victoria, British Columbia, Canada

${ }^{13}$ Sport Sciences, Malmö University, Malmö, Sweden

${ }^{14}$ Nutrition, Exercise and Sports, Copenhagen N, Denmark

${ }^{15}$ Department of Sports Science and Clinical Biomechanics, Faculty of Health

Sciences, University of Southern Denmark, Odense, Denmark

${ }^{16}$ Health Sport and Biosciences, London, UK

${ }^{17}$ Department of Public Health, Section for Sports Science, Aarhus Universitet, Aarhus, Denmark

${ }^{18}$ Department for Research and Development, UC Syddanmark, Esbjerg, Denmark

${ }^{19}$ Institute of School and Learning, Metropolitan University College, Frederiksberg, Denmark

${ }^{20}$ Metropolitan University College, Copenhagen N, Denmark

Twitter Follow Department of Nutrition, Exercise and Sports (NEXS), Copenhagen University at @NEXSKU Symeon Dagkas at @symeondagkas Joan Duda at @JoanDuda and Jesper von Seelen at @jespervonseelen

Competing interests None declared.

Patient consent Obtained.

Provenance and peer review Not commissioned; externally peer reviewed.

Open Access This is an Open Access article distributed in accordance with the Creative Commons Attribution Non Commercial (CC BY-NC 4.0) license, which permits others to distribute, remix, adapt, build upon this work non-commercially, and license their derivative works on different terms, provided the original work is properly cited and the use is non-commercial. See: http://creativecommons.org/ licenses/by-nc/4.0/ 